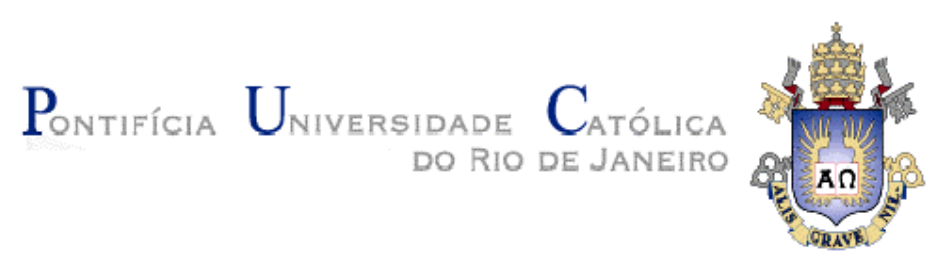

Helena Maria Marques Araújo

\title{
Museu da Maré: \\ entre educação, memórias e identidades
}

\section{Tese de Doutorado}

Tese apresentada ao Programa de PósGraduação em Educação do Departamento de Educação da PUC-Rio como parte dos requisitos parciais para obtenção do título de Doutor em Educação.

Orientador: Prof ${ }^{a}$ Vera Maria Ferrão Candau

Rio de Janeiro Março de 2012 


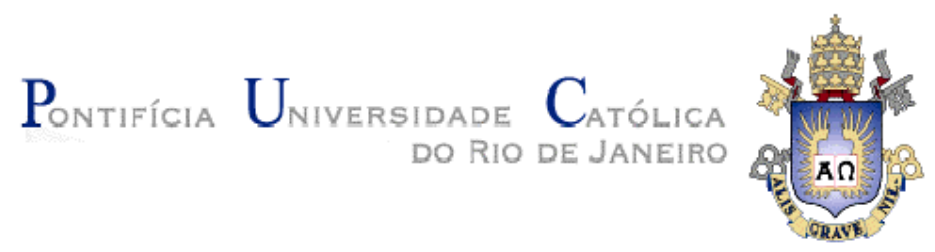

Helena Maria Marques Araújo

\section{Museu da Maré: entre educação, memórias e identidades}

Tese apresentada como requisito parcial para obtenção do título de Doutor pelo Programa de Pós-Graduação em Educação do Departamento de Educação do Centro de Teologia e Ciências Humanas da PUC-Rio. Aprovada pela Comissão Examinadora abaixo assinada.

\section{Prof $^{\mathrm{a}}$ Vera Maria F. Candau} Orientadora

Departamento de Educação - PUC-Rio

Prof. Marcelo Gustavo Andrade de Souza Departamento de Educação - PUC-Rio

Profa . Maria Cristina Monteiro Pereira de Carvalho

Departamento de Educação - PUC-Rio

Prof. Mário de Souza Chagas UNIRIO

\section{Profa . Carmem Teresa Gabriel Anhorn} UFRJ

Profa Denise Portinari Coordenadora Setorial do Centro de Teologia e Ciências Humanas

Rio de Janeiro, 26 de março de 2012. 
Todos os direitos reservados. É proibida a reprodução total ou parcial do trabalho sem autorização da universidade, da autora e do orientador.

\section{Helena Maria Marques Araújo}

Possui graduação em Historia pela Universidade do Estado do Rio de Janeiro (1985) e Mestrado em Educação pela Pontifícia Universidade Católica do Rio de Janeiro (1998). Professora Assistente de História do Instituto de Aplicação- CAp/ UERJ ( Universidade do Estado do Rio de Janeiro) e de Estágio Supervisionado de História no Departamento de História da UERJ. Tem experiência como professora de História na rede municipal e particular de ensino. Atua na área de História e Educação, com ênfase em Ensino de História, Formação Docente, Didática de História, Prática de Ensino e Estágio Supervisionado de História, Memória, Espaços Educativos Não Formais, Museus Comunitários e Ecomuseus.

Ficha Catalográfica

Araújo, Helena Maria Marques

Museu da Maré: entre educação, memórias e identidades / Helena Maria Marques Araújo ; orientadora: Vera Maria Ferrão Candau. - 2012. 238 f. il. ; $30 \mathrm{~cm}$

Tese (doutorado)-Pontifícia Universidade Católica do Rio de Janeiro, Departamento de Educação, 2012. Inclui bibliografia

1. Educação - Teses. 2. Museu da Maré. 3. Museus comunitários. 4. Espaços educativos não formais. 5. Ecomuseus. 6. Memória. 7. Identidade. 8. Nova museologia. I. Candau, Vera Maria Ferrão. II. Pontifícia Universidade Católica do Rio de Janeiro. Departamento de Educação. III. Título.

CDD: 370 
Às minhas memórias:

Aos meus pais, Eugénio (in memorian) e Marilda pela possibilidade da vida, do amor e do ensinamento do valor do estudo.

Aos meus avós, Duarte (in memorian) e Celeste (in memorian) pelo carinho, alegria, saudade e amor pela vida.

À minha irmã, Eugénia, pela amizade, cumplicidade e companheirismo incondicionais.

Aos meus alunos e alunas de todos os tempos e lugares com quem tanto aprendi! 


\section{Agradecimentos}

Ao terminar uma tese de doutorado em Educação e Memória, fazer memória e tornar este um "lugar das minhas memórias” é, no mínimo, desafiador!

É muito difícil até agradecer porque foram tantas as ajudas recebidas, os carinhos, os favores, os apoios, os afagos, as cumplicidades, as benções, as alegrias e tristezas compartilhadas, enfim um muito obrigado a tod@s amig@s, colegas, que comigo caminharam ajudando cada um de sua forma e do jeito como podia!!

Porém, seria uma ingratidão imensa não nomear alguns que partilharam mais de perto esses quatro anos de caminhada acadêmica e existencial!! Portanto, a esses e essas agradeço do fundo de minh alma:

Aos diretores, funcionários e visitantes/ usuários do Museu da Maré sem o qual esta tese não teria acontecido e com os quais compartilho o meu estudo e a minha gratidão. Mas, mais diretamente ao Lourenço Cezar da Silva, Luís Antônio de Oliveira, Terezinha Normandes Lanzellotti, JB (João Batista Henrique), Marilene Nunes da Silva e muito especialmente, ao Carlinhos (Antonio Carlos Pinto Vieira) pelo tempo repartido em todas as atividades que fizemos e por ter me recebido desde o início com incansável generosidade, profissionalismo, dinamismo e boa vontade, sempre!!

Aos pescadores dos três Núcleos de Pesca da Maré e do Canal do Fundão: Núcleo de Pesca da Vila do Pinheiro, Núcleo de Pesca do Parque União e Núcleo de Pesca da Vila Residencial da UFRJ minha gratidão, com quem também compartilho parte deste estudo e que me geraram tanto encantamento com o tema estudado. Pela sabedoria, generosidade e exemplo de vida com que nos presentearam nas entrevistas concedidas, sem as quais parte deste trabalho também não teria acontecido!!

À minha querida e sempre professora, orientadora, Vera Maria Candau, pela sua orientação segura, competente, amiga e tranquila. Mas, especialmente por ter 
aceito o desafio junto comigo dessa orientação por águas tão "novas", ou melhor por "marés" tão desconhecidas para nós!!

Ao meu querido coordenador de pesquisa na PUC-Rio, Marcelo Andrade, amigo antigo e "chefe de pesquisa", por sua competência teórica, metodológica, mas acima de tudo relacional, ao conduzir o grupo do também GECEC de forma tão brilhante e humana. A ele, minha admiração e gratidão!

Aos professores da Pós-graduação com quem tanto aprendi e compartilhei momentos de estudo e conversas! Especialmente agradeço às professoras Alicia Bonamino e Ana Waleska Mendonça pelo carinho e interlocução acadêmica desde o mestrado. Grata também fico à prof. Sonia Kramer pelo aprendizado como ouvinte em suas aulas sobre os textos de Benjamin e à prof. Rosália Duarte pelas discussões metodológicas coletivas em sala. Também sou grata à professora Isabel Lélis que, com sua tese, me foi fonte de inspiração.

Aos professores que participaram generosamente das minhas duas bancas de Qualificação indicando caminhos, análises e me auxiliando com sugestões valiosas na pesquisa teórica e no trabalho de campo: Carmem Gabriel, Cristina Carvalho e Mário Chagas.

Um singular agradecimento ao Professor Manoel Salgado Guimarães (in memorian) por tanto ter me ensinado de forma tão generosa e competente no estudo individual sobre Memória com que me ofertou. Onde quer que você esteja no plano espiritual, Manoel, receba o meu eterno muito obrigado!!

Ao professor Mário Chagas um especial agradecimento pelas trocas profícuas e pelo material teórico generosamente indicado, cedido e compartilhado.

À Cláudia Mesquita, pelas interlocuções atentas, preciosas e amigas durante todo este percurso desde o mestrado.

A todo o grupo de pesquisa do GECEC no qual passamos estudando, analisando, trabalhando, mas também conversando e rindo, as nossas sextas-feiras à tarde durante quase quatro anos!! Muito especialmente aos amigos e colegas que já tínhamos, se fortaleceram ou se fizeram na caminhada: Cláudia Miranda, Paulo 
Rebello, Anna Carolina Barbosa, Eliana Palmeira, Luiz Câmara, Pedro Teixeira, Viviane Amorim, Raquel Alexandre, Mônica Almeida, Monique Longo, Pamela Cruz, Giselma Sampaio e Patrícia Nascimento.

Aos queridíssimos estagiários Rodrigo Goulart, Raquel Jerez e Laysa Rosa, assim como ao meu filho Daniel, que fizeram o trabalho "insano" e cuidadoso das transcrições das entrevistas.

Ao Leopoldo Erthal, que apesar de tão jovem, manejou com tanta habilidade a confecção dos dados transformando-os nos gráficos aqui utilizados.

Aos meus colegas do curso de doutorado aonde iniciamos os desafios, crises e questionamentos acadêmicos juntos através de conversas com muitos biscoitos, risos e angústias, mas especialmente à Cinthia Araújo, à Daniela Valentim e à Roberta Araújo, companheiras de mesmo barco! Mas, especialmente ao José Roberto Rodrigues pela amizade, cumplicidade e solidariedade que se fizeram e só se ampliaram ao longo desses quatro anos!

A Ana Maria Santiago, querida amiga e coordenadora do Projeto DaMARÉ, que não só me auxiliou como me permitiu através do Projeto uma entrada quase "antropológica" no campo. A ela minha enorme gratidão pela confiança depositada na escolha de meu nome para a coordenação do Grupo de Memória junto a Antonio Carlos Pinto Vieira.

Ao Grupo de Memória do Projeto da DaMARÉ, com quem elaborei parte de meu estudo me possibilitando diversas investidas e conhecimento do campo e da Maré, nas presenças de Humberto Salustriano da Silva, Terezinha Normandes Lanzellotti e Stela Caputo.

Ao Arquivo Nacional, na presença de seu diretor, Prof. Jaime Antunes, pela concessão das imagens ao Grupo de Memória do Projeto DaMARÉ, algumas por mim utilizadas também nessa tese.

À UERJ (Universidade do Estado do Rio de Janeiro) pela licença de doutoramento (PROCAD) concedida por dois anos me permitindo o afastamento 
das atividades docentes e administrativas para maior dedicação e concentração na minha pesquisa de doutoramento.

Ao CAp/ UERJ pela força sempre dada aos pedidos de concessão e renovação da licença de PROCAD, especialmente aos diretores e amigos, Miguel Mathias pelo carinho, amizade e compreensão em todos esses momentos e à Lícia Maria Vieira Vasconcellos, pela grata amizade e luta incansável na concessão da minha licença.

À equipe de História do CAp/UERJ por estimular minha saída de licença através de votação sempre favorável a que esta iniciativa se concretizasse na instituição.

Aos professores contratados de História do CAp/UERJ que com tanto carinho e dedicação me substituíram nas minhas turmas da graduação e do CAp/UERJ: Thiago Florêncio e Lucas Barros. Mas, um especialíssimo agradecimento ao Márcio Romão, ex-aluno, colega, querido amigo, que vêm compartilhando comigo nos últimos anos de forma tão solidária todas essas lutas e conquistas.

Aos amigos e colegas do CAp/UERJ com quem compartilhamos lutas e sonhos por uma educação pública, de qualidade e efetiva, especialmente ao Lincoln Tavares da Silva, Maria Beatriz Porto, Andréa Fernandes e Maria Cristina Ferreira dos Santos.

Ao Paulo Rogério Silly, querido colega de História, que me fez a sugestão do tema de estudo da tese me levando à "descoberta" do Museu da Maré!

À Joana D`Arc Ferraz por ter me apresentado e aproximado do "pessoal” do Museu da Maré.

À querida médica/ amiga, Dra. Gláucia de Azevedo Saad, pela generosidade e competência em manobrar suas "agulhas mágicas" que me revigoraram quase toda a semana suportando melhor a "caminhada acadêmica"!!

À Dra. Cândida Maria Camargo que me auxiliou guiando pelos caminhos do inconsciente no início desta jornada e à Dra. Veronika Penãloza por ter me oportunizado um mergulho mais profundo na procura de mim mesma através das minhas "lembranças" e "memórias subterrâneas"! 
A todo o pessoal do União Fraterna, particularmente à Kika, Lena, Mariângela, Dora e Sônia.

À Cátia Regina de Souza pela incansável presença no cuidado com nossa família.

Aos amigos antigos e novos: Cristina Ferreira, Sandra Andrade, Antonio Mendonça, Hilton Meliande, Dirceu Castilho Pacheco, Renata Augusta e Ronaldo Padilha que em momentos diferenciados se fizeram presentes durante toda esta jornada.

À Biba, um "anjo" disfarçado posto em nossa casa, que tanta alegria, ternura e companhia me fez durante os inúmeros dias e noites de estudo e intensa "solidão acadêmica"!

Ao meu filho Pedro, tão atento, solidário e prestativo em seus carinhos e cuidados comigo especialmente nos momentos finais desta tese.

À Beatriz, queridíssima sobrinha e afilhada, pelo amor, superação e alegria com que leva a vida!

Ao Felipe, querido enteado, por sua amizade e presença me provando desde nova que "Tudo vale a pena, se a alma não é pequena"!!!

Ao Daniel e Pedro, filhos amados, "amores da minha vida", meus "tesouros históricos", minha gratidão por existirem e meu amor infinito!!!!!!!!

À espiritualidade maior, a gratidão eterna pela vida!!! 


\section{Resumo}

Araújo, Helena Maria Marques; Candau, Vera Maria. Museu da Maré: entre educação, memórias e identidades. Rio de Janeiro, 2012. 238p. Tese de doutorado - Departamento de Educação, Pontifícia Universidade Católica do Rio de Janeiro.

A pesquisa entrelaça memória, espaços educativos não formais e identidade. O objetivo central é analisar a dimensão educativa do Museu da Maré no Rio de Janeiro e suas possibilidades de contribuição para o fortalecimento identitário de grupos populares através da valorização e ressignificação da história e da construção das memórias locais. Abordo o conceito, os pressupostos teóricos e desafios dos museus comunitários como espaços educativos não formais, enfocando como estudo de caso o Museu da Maré.

Os museus comunitários e ecomuseus emergem no Rio de Janeiro com o Ecomuseu de Santa Cruz em 1983, porém ganham visibilidade com o Museu da Maré a partir de 2006, por ser este o primeiro museu de favela no Brasil criado pela própria comunidade.

O quadro teórico baseou-se para o conceito de memória, principalmente em Paul Ricoeur, Jacques Le Goff e Beatriz Sarlo. Para o de identidade utilizamos Stuart Hall, Manuel Castells, Vera Maria Candau e Tomaz Tadeu da Silva. Para espaços educativos não formais privilegiei Maria Glória Gohn, Jaume Trilla e Elie Ganem. Por fim, para os conceitos da Nova Museologia, museu comunitário e ecomuseu me apoiei basicamente em Mário Chagas e Hugue de Varine.

De inspiração etnográfica, meu caminho metodológico baseou-se na história oral. Na pesquisa de campo utilizou-se três tipos de aproximações ao objeto de estudo: observação de diferentes atividades desenvolvidas no Museu e de diversos ambientes da comunidade em geral, entrevistas semiestruturadas feitas aos pescadores da Maré e aos diretores e funcionários do Museu da Maré e análise dos Livros institucionais do Museu, a saber: o Livro de Assinaturas e o Livro de Depoimentos dos visitantes. 
Como uma das principais conclusões de minha pesquisa sobre a dimensão educativa do Museu da Maré posso afirmar que me deparei de fato com um Museu que tem significado para a região da Maré e dialoga com a cidade, o país e outros lugares, embora não represente totalmente todas as suas comunidades. No entanto, ele se fez comunitário, na medida em que foi criado e tem a participação cotidiana do movimento social e da comunidade local de seu entorno.

Além disso, o fato do Museu da Maré apresentar uma linguagem museográfica que suscita referências da história local e permite que seus visitantes reflitam sobre as mesmas, se emocionem e construam memórias locais possibilitando através das mesmas um fortalecimento identitário, torna especialmente evidente e significativa sua dimensão educativa.

Por fim, o Museu da Maré gera visões “de nós e dos outros" estabelecendo um jogo sutil e constante entre identidades e alteridades em suas memórias construídas e histórias narradas.

\section{Palavras-chave:}

Museu da Maré; museus comunitários; espaços educativos não formais; ecomuseus; Memória; Identidade; Nova Museologia. 


\section{Abstract}

Araújo, Helena Maria Marques; Candau, Vera Maria (Advisor). Maré's Museum: between education, memories and identities. Rio de Janeiro, 2012. 238p. Thesis - Departamento de Educação, Pontifícia Universidade Católica do Rio de Janeiro.

The research intertwines memory, non-formal educational spaces and identity. The main objective is to analyze the educational dimension of the Maré Museum in Rio de Janeiro and its possible contributions to the strengthening of the group identity related to popular groups through appreciation and reinterpretation of the history and construction of local memories. I approach the concept, the theoretical assumptions and challenges of community museums as non-formal educative spaces, by using the Maré Museum as a case study .

The community museums and ecomuseums emerge in Rio de Janeiro with the Eco-museum of Santa Cruz in 1983, but became more visible with the Maré Museum as of 2006, since this is the first museum in Brazil's slums created by the community itself.

The theoretical framework related to the concept of memory was essentially based on work of Paul Ricoeur, Jacques Le Goff and Beatriz Sarlo. For the theoretical framework associated with identity development, I have chosen the studies performed by Stuart Hall, Manuel Castells, Vera Maria Candau and Tomaz Tadeu da Silva. For the non-formal educational spaces theoretical basis I have privileged Maria Gloria Gohn, Jaume Trilla and Elie Ganem. Finally, for the concepts of New Museology, community museum and ecomuseum I rely primarily on Mario Chagas and Hugue de Varine.

My methodological approach of ethnographic inspiration was based on oral history. In the field research I used three types of approaches to the object of study: observation of different activities in the Museum and of the community at large, semi-structured interviews to fishermen of the Maré and to the directors and staff of the Museum of the Maré and analysis of the institutional books of the 
Museum, namely the Book of Signatures and the Book of Testimonies from visitors.

As one of the main conclusions of my research on the educational dimension of the Mare Museum I can state that this museum does have meaning for the region of Maré and dialogues with the city, the country and elsewhere, although it does not fully represent all its communities. However, this museum has been able to develop a community related feature, as it was created by and has the daily involvement of the social movement and the local community of their surroundings.

Moreover, the fact that the Mare Museum display a museographic language which raises references of local history and allows visitors to reflect on them and build local memories enabling a strengthening of identity, makes its educative dimension particularly evident and significant.

Finally, the Maré Museum generates visions "of ourselves and others" by establishing a more subtle and constant dynamic between individuals' identities and their constructed memories and narrated stories.

\section{Key-words:}

Maré`s Museum; community museums; non-formal educative spaces; ecomuseums; Memory; Identity; New Museology. 


\section{Sumário}

1. Introdução, ou como cheguei a meu objeto de estudo ................ 24

2. De quais memórias e identidades estamos falando? ................ 43

2.1. As "diferentes" memórias ..................................................... 43

2.1.1. A memória em Jacques Le Goff ...................................... 43

2.1.2. A memória em Paul Ricoeur ......................................... 45

2.1.3. A memória em Beatriz Sarlo .......................................... 48

2.2. Os diferentes conceitos de identidade ............................... 51

2.2.1. O contexto histórico do surgimento do multiculturalismo ....... 51

2.2.2. O que chamamos identidade (s) ..................................... 52

3. Na "Maré" da Nova Museologia ......................................... 67

3.1. Do colecionismo dos Gabinetes de Curiosidades ao protagonismo comunitário dos Ecomuseus ................................ 67

3.2. O que são os museus comunitários e ecomuseus? Por que e para que os museus comunitários e os ecomuseus ..................... 75

3.3. Panorama geral dos museus comunitários no Rio de Janeiro .. 80

4. Onde fica a educação nisso tudo? ......................................... 86

4.1. Não é só na escola que se educa ......................................... 86

4.1.1. A educação não formal não é informal ................................ 86

4.1.2. Contexto e fatores do desenvolvimento da educação não

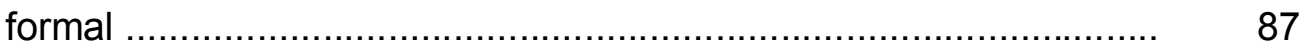

4.2. Os "lugares de memória" também educam .......................... 93

5. A história da Maré, como tudo começou ................................. 95

5.1. Do mar ao "sertão" ............................................................... 99

5.2. Da favela ao bairro ...................................................... 108

5.3. A criação do Museu da Maré ............................................... 117 
6. Que "peixes" pescamos no Museu da Maré? ……………….... 128

6.1. Apresentando os pescadores entrevistados .......................... 128

6.2. Memórias e lembranças dos pescadores ............................... 135

6.3. A rede da memória constrói a identidade dos pescadores ....... 143

7. "Os narradores da Maré" ............................................................. 154

7.1. Quem são "os narradores"? ................................................... 154

7.2. Afinal de contas, o que eles querem narrar? .......................... 156

7.2.1. "Por que o museu em favela?" .............................................. 156

7.2.2. "Porque ele nasce desse projeto político de identidade e pertencimento" ................................................................. 162

7.2.3. "O Museu conta minha história, a minha história da infância..."

7.2.4. "O Museu da Maré é um aparelho muito visual e auto educativo"

7.3. Retomando as narrativas ou "A possibilidade de você se emocionar!"

8. Das presenças e das ausências nos Livros de Assinaturas e Depoimentos, ou a hora e a vez das "memórias subterrâneas"

8.1. O Livro de Assinaturas

8.1.1. Visitantes do ano de 2009

8.1.2. Visitantes do ano de 2010

8.1.3. Entrecruzando os dados

8.2. O Livro dos Depoimentos 204

8.2.1. De visitante a usuário: acompanhando Brenda 204

8.2.2. Os eixos temáticos 209

8.2.3. Que aspectos podemos destacar?

9. "Marés de memórias" ou "memórias de Marés" 


\section{Lista de Gráficos}

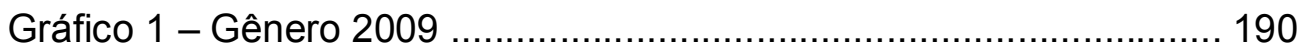

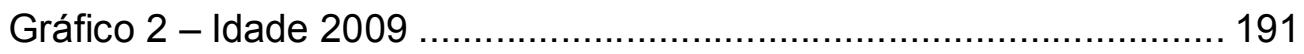

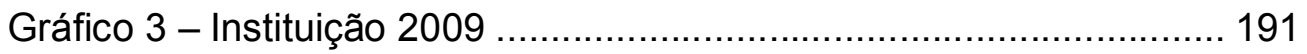

Gráfico 4 - Origem: Comunidades da Maré 2009 ................................ 193

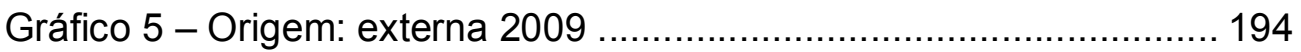

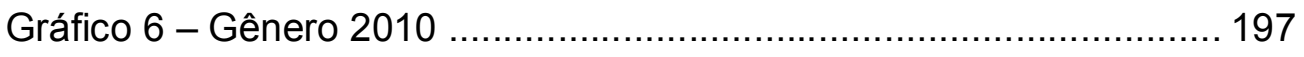

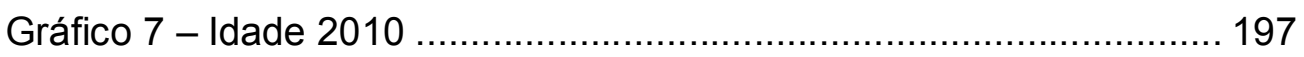

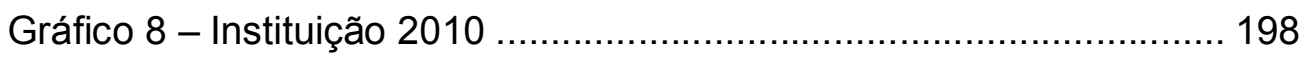

Gráfico 9 - Origem: Comunidades da Maré ……………..................... 199

Gráfico 10 - Origem total dos visitantes do Museu da Maré ................. 200

Gráfico 11 - Origem externa ao Complexo da Maré ............................. 201 


\section{Lista de Fotos}

Foto 1 - Interior do Ecomuseu de Santa Cruz ................................ 81

Foto 2 - Fachada da sede do Ecomuseu de Santa Cruz ................ 82

Foto 3 - Associação dos Moradores do Cantagalo no percurso do MUF

Foto 4 - Início do percurso do MUF

Foto 5 - Fachada de casa contando a história da comunidade no percurso do MUF

Foto 6 - Percurso no território do Museu do Horto

Foto 7 - Percurso no território do Museu do Horto

Foto 8 - Fachada da entrada do Museu da Maré

Foto 9 - Vista panorâmica dos "alagados" da Maré com suas palafitas até à década de 80

Foto 10 - Praia do Apicú, atual região da Maré

Foto 11 - Instituto Oswaldo Cruz com Baía de Guanabara ao fundo e llhas do Pinheiro e do Fundão

Foto 12 - Ilha do Pinheiro, pertencente ao Instituto Oswaldo Cruz ..

Foto 13 - Região do Aeroporto de Manguinhos

Foto 14 - Aterro da década de 70 feito com o Projeto Rio

Foto 15 - Baía de Guanabara com llha do Fundão após anexação das outras ilhas do entorno; llha do Pinheiro ainda separada e ponte de ligação com a llha do Governador

Foto 16 - Imagem emblemática das palafitas nos alagados da Maré: Baixa do Sapateiro e Parque Maré

Foto 17- "Pontes de tábuas" interligando as palafitas da Maré

Foto 18 - Prédio amarelo: embaixo, a biblioteca; em cima, salas de cursos; atrás, salas de informática e o Arquivo D.Orosina Vieira

Foto 19 - Prédio vermelho: exposição permanente do Museu da Maré 
Foto 21 - A emblemática palafita na entrada da exposição permanente do Museu ............................................................ 120

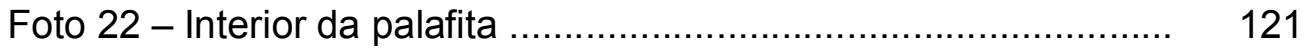

Foto 23 - Interior da palafita e visão da favela pelo banner externo 121

Foto 24 - Cenário externo à palafita, mulher com lata de água na cabeça e varal de roupas ...................................................... 122

Foto 25 - Os registros de posse das casas, jornal local e fotos ....... 123

Foto 26- O tempo dos "barracos" acabou, surgem as casas de alvenaria e seu cotidiano ....................................................... 124

Foto 27 - Anexo de exposições temporárias no Museu da Maré ..... 125

Foto 28 - Loja "Arte da Maré" de vendas de artesanato e costuras das Marias Maré no pátio do Museu .............................................. 125

Foto 29 -Píer do Núcleo de Pesca da Vila Residencial da UFRJ .... 128

Foto 30 - Vila Residencial da UFRJ com obras de saneamento ..... 129

Foto 31 - Píer do Núcleo de pesca da Vila do Pinheiro .................. 129

Foto 32 - Ancoradouro de barcos do píer da Vila do Pinheiro e o vão da Linha Vermelha por cima ................................................. 130

Foto 33 - Píer do Núcleo de Pesca do Parque União e o vão da Linha Vermelha por cima .......................................................... 130

Foto 34 - Píer da do Núcleo de Pesca da Vila do Pinheiro ............. 131

Foto 35 - "Seu" Jaqueta ........................................................... 132

Foto 36 - Pescadores da Vila Residencial da UFRJ: "Seu" Foca, "Seu" Carlos e "Seu" Cordeiro ...................................................... 134

Foto 37 - O pescador Siri na entrevista realizada dentro do Museu

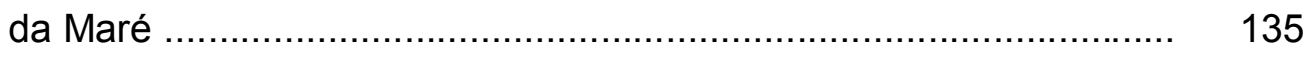

Foto 38 - Vovô contando suas histórias na entrevista .................... 139

Foto 39 - Píer do Núcleo de Pesca da Vila do Pinheiro .................. 142

Foto 40 - Píer do Núcleo de Pesca da Vila Residencial da UFRJ ... 142

Foto 41 - "Seu" Foca ............................................................... 145

Fotos 42 e 43 - Imagens de São Pedro, Nossa Sra. de Aparecida e lemanjá no píer do Núcleo de Pesca da Vila do Pinheiro

Foto 44 - Poluição do Canal do Fundão visto daVila Residencial da UFRJ 
Foto45 - Linha Vermelha ao fundo, embaixo da autoestrada o Núcleo de Pesca da Vila do Pinheiro. Poluição do Canal do Fundão vista da llha do Fundão ................................................. 148

Foto 46 - Poluição no Canal do Fundão ....................................... 148

Foto 47 - Pescador Marcos do Parque União ………………….... 149

Foto 48 - "Chá de memória" no pátio do Museu da Maré em 2011 . 174

Foto 49 - "Chá de memória" com um dos contadores de histórias

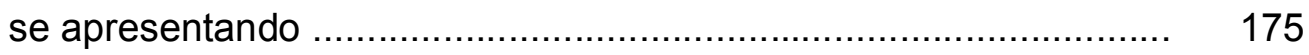

Foto 50 - Alunos de escola municipal visitando o Museu da Maré recebendo informações do arte educador do Museu na entrada da exposição permanente ............................................... 192

Foto 51 - Painel na entrada da exposição permanente do Museu da Maré .................................................................................. 223 


\section{Lista de mapas}

Mapa 1: Área total do estado do Rio de Janeiro com destaque para a

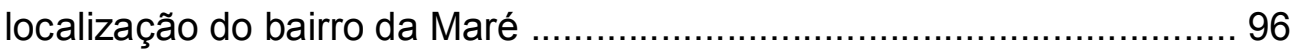

Mapa 2: Bairro da Maré com destaque para 16 comunidades ............... 97 


\section{Lista de Abreviaturas e siglas}

ABREMC - Associaçaõ Brasileira de Ecomuseus e Museus Comunitários

BNH - Banco Nacional de Habitação

CAp/ UERJ - Instituto de Aplicação Fernando Rodrigeus da Silveira da UERJ

CBPF - CENTRo BRASILEIRO de PESQUISAS Físicas

CEASM - Centro de Estudos e Ações Solidárias da Maré

CENPES/ PETROBRÁS - Centro de Pesquisas e Desenvolvimento Leopoldo Miguez de Mello / PETROBRÁS

CEDAE - Companhia Estadual de Água e Esgoto

CHP - Centro de Habitação Provisória

CIEP - Centro Integrado de Escola Pública

DNOS - Departamento Nacional de Obras e de Saneamento

ENSP - Escola Nacional de Saúde Pública da FIOCRUZ

FAPERJ - Fundação de Amparo à Pesquisa no Estado do Rio de Janeiro

FGV - Fundação Getúlio Vargas

FIOCRUZ - Fundação Osvaldo Cruz

GECEC - Grupo de Estudos sobre o Cotidiano, Educação e Culturas

ICOM - Conselho Internacional de Museus

IPHAN - Instiuto do Patrimônio Histórico e Artíscico Cultural

MASP - Museu de São Paulo

MAST - Museu de Astronomia e Ciências Afins

MINOM - Movimento Internacional da Nova Museologia

MUF - Museu de Favela (do Pavão-Pavaozinho e Cantagalo)

NEPE - Núcleo de Editoração, Pesquisa e Extensão do CAp/ UERJ

NOPH - Núcleo de Orientação e Pesquisa Histórica 
PROMORAR - Programa de Erradicação da Sub-habitação

PROVOC - Programa de Vocação Científica

SEA - Secretaria Estadual de Ambiente

UERJ - Universidade do Estado do Rio de Janeiro

UFRJ - Universidade Federal do Rio de Janeiro

UNIRIO- Universidade Federal do Estado do Rio de Janeiro

UPP - Unidade de Polícia Pacificadora 
Somos a memória que temos e a responsabilidade que assumimos. Sem memória não existimos, sem responsabilidade talvez não mereçamos existir."

José Saramago 